\title{
Patient navigation programs in Alberta, Canada: an environmental scan
}

\author{
Karen L. Tang MD MSc, Jenny Kelly MA, Nishan Sharma EdD, William A. Ghali MD MPH
}

\section{Abstract}

Background: Patient navigation is a complex intervention that has garnered substantial interest and investment across Canada. We conducted an environmental scan to understand the landscape of patient navigation programs within the health care system in Alberta, Canada.

Methods: We included patient navigation programs within Alberta Health Services (AHS) and Alberta's Primary Care Networks (PCNs). Key informants were asked in October 2016 to identify existing programs and their corresponding program contacts. These program contacts were invited to complete a telephone-based survey from October 2016 to July 2017, to provide program descriptions and eligibility criteria, and to identify gaps in navigation. Programs were included if they engaged patients on an individual basis, and either facilitated continuity of care or promoted patient and family empowerment. We tabulated results and calculated summary statistics for program characteristics.

Results: Ninety-five potentially eligible programs were identified by key informants. The response rate to the study survey was $73 \%$ $(n=69)$. After excluding programs not meeting inclusion criteria, we included a total of 58 programs in the study: 43 AHS programs and 15 PCN programs. Nearly all programs $(93 \%, n=54)$ delivered navigation via an individual acting as a navigator. A minority of programs also included nonnavigator components, such as Web-based resources $(7 \%, n=4)$ and process or structural changes to facilitate navigation $(22 \%, n=13)$. Certain patient subgroups were particularly well-served by patient navigation; these included patients with cancer, substance use disorders or mental health concerns, and pediatric patients. Gaps identified in navigation fell under 4 domains: awareness, resources, geographic distribution and integration.

Interpretation: Patient navigation programs are common and have extended beyond cancer care, from which the construct originated; however, gaps include a lack of awareness and inequitable access to the programs. These findings will be of interest to those developing and implementing patient navigation interventions in Alberta and other jurisdictions.

\begin{abstract}
[ $\mathrm{n}$ health systems everywhere, there is an overwhelming array of health care services, payers and providers. The burden of responsibility of navigating such a complex and patchy system defaults to patients and their families. ${ }^{1-3}$ Patient navigation is a complex intervention that arose to address health disparities stemming from the fragmentation of the health care system. The first program was created in 1990 in Harlem, New York, where "patient navigators" worked with patients directly to identify barriers to breast cancer diagnosis and treatment, and then connected them with resources to address these barriers. ${ }^{4-6}$ From this intervention, the construct of patient navigation was born.

In the broadest sense, patient navigation "[facilitates] patients' receipt of care from providers" and "[improves] continuity and coordination of care," though a standard definition remains elusive. ${ }^{7,9,10}$ Although early interventions were modelled after the original Harlem experience, patient navigation has extended beyond these bounds. First, it is no longer confined to the cancer care continuum, having been
\end{abstract}

used for patients without cancer to coordinate primary and specialist care, facilitate transitions from acute (hospitalbased) care to outpatient care, and connect patients to community organizations and resources. ${ }^{11-24}$ Second, though most interventions still depend on individual navigators, ${ }^{25-27}$ navigation can alternatively be achieved through system-level interventions and Web- or paper-based resources. ${ }^{28-32}$

Despite the growth in both the number and variety of patient navigation programs across North America, the

Competing interests: Karen Tang and William Ghali report a grant from the Canadian Institutes of Health Research for another project related to patient navigation. No other competing interests were declared.

This article has been peer reviewed.

Correspondence to: Karen Tang, klktang@ ucalgary.ca

CMAJ Open 2021 September 7. DOI:10.9778/cmajo.20210004 
current landscape in this area remains unclear. Specifically, whether patient navigation programs exist for patients across the age spectrum, whether populations with certain diseases are better resourced with more programs and what gaps remain in intervention delivery remain unknown. In Alberta, Canada, there has recently been substantial investment into patient navigation. We conducted an environmental scan with the objective of identifying and describing patient navigation programs within the health care system in Alberta.

\section{Methods}

\section{Study design and setting}

Environmental scanning is "the process of seeking, gathering, interpreting and using information from the internal and external environments of an organisation to inform strategic decision-making." ${ }^{3} 3$ There is no standard way by which environmental scans are conducted, ${ }^{33-35}$ though the common goal is to identify environmental gaps and opportunities to inform an organization's future steps. ${ }^{34}$ To understand better the scope of services delivered by the provincial health authority, we undertook an environmental scan of patient navigation programs within Alberta Health Services (AHS) and Alberta's Primary Care Networks (PCNs, or team-based medical homes providing primary care). About $80 \%$ of primary care physicians in Alberta are a part of a PCN, and nearly 3.8 million Albertans (about $85 \%$ of the population) receive care at a $\mathrm{PCN} .{ }^{36}$

The environmental scan was conducted in 2 phases. In phase 1 , we identified patient navigation programs within AHS and the PCNs via key informants. In phase 2, the contacts of these programs were invited to complete a telephone-based survey about program characteristics and patient navigation gaps.

\section{Phase 1: recruitment}

An email to key informants, requesting assistance in identifying patient navigation programs in Alberta, was sent on Oct. 3, 2016, from the office of the Vice President (Quality) and Chief Medical Officer of Alberta Health Services. Key informants were AHS senior leaders, which included directors, senior provincial directors, executive directors, senior program officers and senior operating officers for the different facilities and portfolios across the province. They were asked to email the study team with a list of the patient navigation programs within AHS or the PCNs known to them, and the name and contact information of individuals involved with the programs. Two email reminders were sent to encourage participation. The recruitment period ended on Oct. 31, 2016, with no further responses received after that date.

\section{Phase 2: survey}

A survey (Appendix 1, available at www.cmajopen.ca/ content/9/3/E841/suppl/DC1) of program characteristics was created (K.L.T. and W.A.G.). Characteristics of interest included eligibility criteria, description of program activities, frequency and duration of follow-up, and geographic regions served. The survey was tested and reviewed by 3 AHS leaders - a member of the executive leadership team, a senior provincial director and the director of operations for an AHS navigation program. Feedback about the content, response choices and wording of the questions was specifically elicited. The survey was found to be feasible, acceptable and clear. Based on feedback, the survey was revised to add questions about program model of delivery and identified gaps.

Two study team members (J.K. and N.S.) compiled a list of patient navigation programs and program contacts identified in phase 1. A study invitation email was sent to the program contacts, with 2 reminder emails spaced 1 week apart. The study survey was administered via a telephone interview, by a study team member with mixed-methods experience (J.K.), from October 2016 to July 2017. Interviews were not audio recorded. All data, including responses to open survey questions (which were transcribed concurrently during the interview), were stored in REDCap, a Web-based datamanagement application.

\section{Inclusion criteria}

Because there is no single standard definition of patient navigation, inclusion criteria for patient navigation programs to be included in data analysis were intentionally broad, combining multiple definitions. Programs were included if they engaged patients on an individual basis (i.e., were not solely provider-facing), ${ }^{37-39}$ and either facilitated continuity of care (i.e., linking patients to providers or services) or promoted patient and family empowerment (e.g., through provision of information or by helping to overcome barriers to support health needs). ${ }^{40}$

It is widely recognized that there is overlap between patient navigation and related constructs such as advocacy, case management, outreach and education. ${ }^{9}$ Programs were included if they met inclusion criteria, regardless of the training and background of the navigator (e.g., nursing, social work, lay person), consistent with the patient navigation literature. . 51,42 Programs not administered by AHS or a PCN were excluded. Duplicate programs were excluded.

\section{Data analysis}

The unit of analysis was the program. Descriptive information about programs was presented in a tabular format. Summary statistics were calculated for program characteristics (K.L.T.), and all results were stratified by whether programs were administered by AHS versus the PCNs. Geographic coverage for each program was categorized into the 5 AHS zones: North, Edmonton, Central, Calgary and South Zones. Programs were further categorized (J.K. and K.L.T) into 3 groups based on method of delivery: patient navigator, ${ }^{11-24}$ Web- or paper-based resources to facilitate self-navigation, ${ }^{25-27}$ and structural or organization changes to facilitate increased efficiency and coordination of care. ${ }^{28}$ The categories were not mutually exclusive, and programs could be placed into more than 1 category. Disagreements were resolved by a third investigator (W.A.G.). 
Free-text responses to the survey question asking about gaps in patient navigation were analyzed using thematic content analysis. ${ }^{43,44}$ Because the goal was to identify gaps in services, rather than forming or exploring complex theory, a qualitative descriptive approach was undertaken. ${ }^{45,46}$ One physician study team member with no personal or professional experience with patient navigation (K.L.T.) performed open coding, identifying codes relevant to study objectives. These codes were organized into broader themes capturing different domains of patient navigation gaps. Themes were derived from data rather than being predetermined, consistent with an inductive approach. Review and interpretation of codes and the development of themes were undertaken through regular meetings between members of the study team (K.L.T. and W.A.G.). A record of decisions and changes was kept.

\section{Ethics approval}

The study was approved by the Conjoint Health Research Ethics Board at the University of Calgary.

\section{Results}

In phase 1, 39 key informants identified a total of 144 programs. Of these, 49 were excluded (Figure 1). In phase 2, we requested telephone interviews with the primary contacts of the remaining 95 programs. We had a $73 \%$ program response rate, completing interviews for 69 programs. Of these, another 11 were excluded, leaving 58 programs in this environmental scan (43 AHS programs and $15 \mathrm{PCN}$ programs; Appendix 2 available at www.cmajopen.ca/content/9/3/E841/ suppl/DC1).

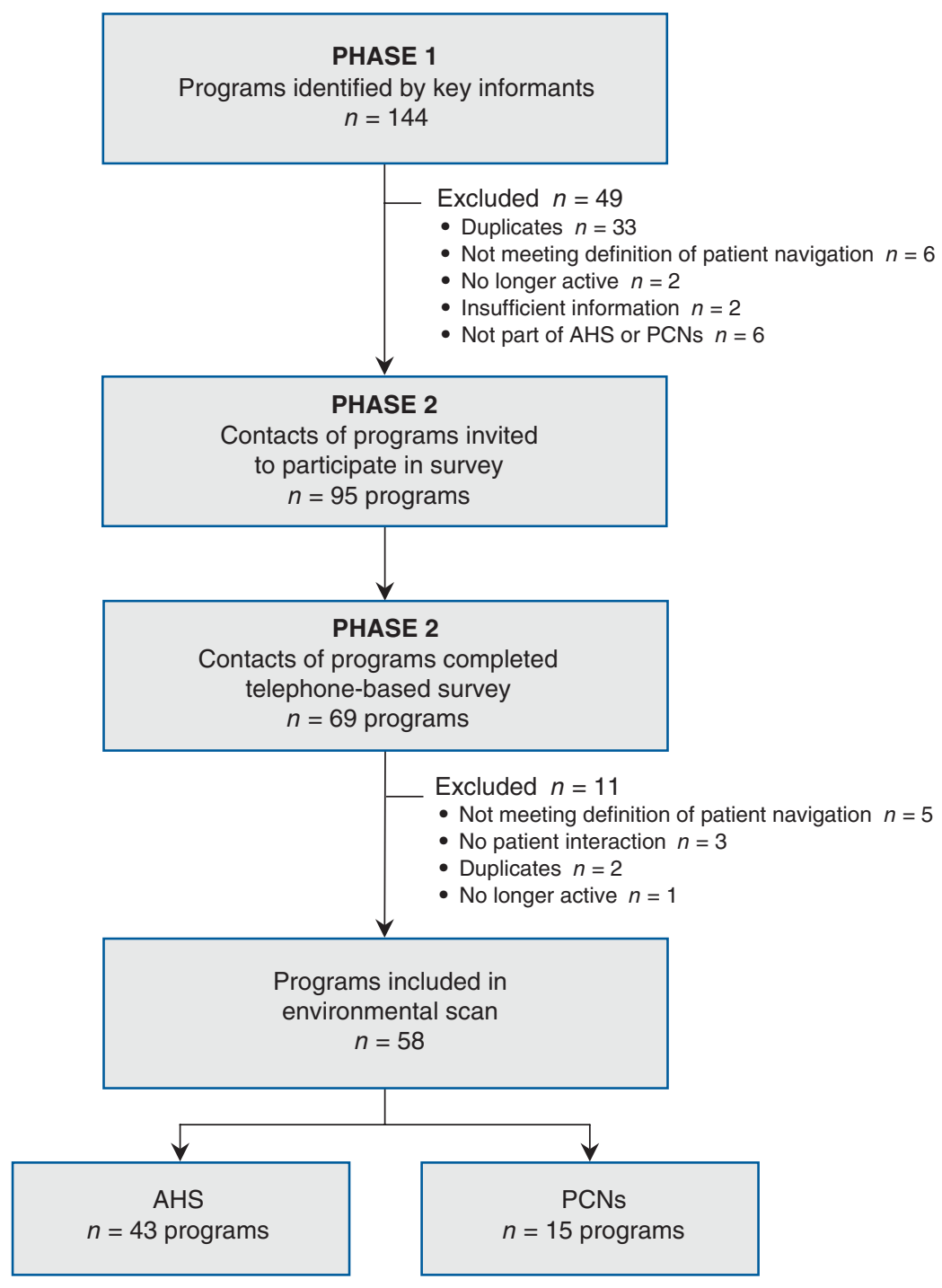

Figure 1: Flow diagram of study phases and recruitment. Note: AHS = Alberta Health Services, PCN = Primary Care Network. 


\section{Program characteristics}

\section{Patient eligibility}

Most of the included programs were accessible by patients of all ages (see Table 1 for a summary of program characteristics and Appendix 2 for a description of each program). Of the AHS programs, 16 (37\%) were specific to children, and $1(2 \%)$ was specific to older adults ("seniors"). In contrast, none of the 15 PCN programs offered pediatric- or geriatric-specific navigational services. Most AHS programs were specifically targeted to patients with certain clinical conditions (most commonly those with cancer, substance use disorders and mental health concerns, or developmental or neurologic conditions). Of the 15 PCN programs, $14(93 \%)$ were available to patients of all ages, with $9(60 \%)$ programs not targeting a specific condition. More than one-third of both AHS and PCN programs allowed self-referral. Nearly all programs were outpatient based, with only $2(5 \%)$ of the AHS programs serving the inpatient population.

\section{Geographic coverage}

Nearly half of the AHS programs $(44 \%, n=19)$ were offered in the Calgary Zone. The second most-served region was the Edmonton Zone, with 9 (21\%) of 43 programs offered there. Nearly a quarter of the AHS programs $(23 \%, n=10)$ were available province-wide. Most PCN programs $(53 \%, n=8)$ served towns and cities in the Central Zone. Four (27\%) of the PCN programs were available to residents in the North Zone, and 3 (20\%) were available in the Edmonton Zone, with no programs identified in the Calgary or South Zones. There were no province-wide PCN programs.

\section{Classification of programs}

Appendix 3, available at www.cmajopen.ca/content/9/3/E841/ suppl/DC1, categorizes programs by method of delivery. Nearly all programs $(93 \%, n=54)$ included a dedicated individual acting as a navigator to direct patients to appropriate resources and services, or to help identify and overcome barriers to accessing care. Thirteen programs (10 AHS and $3 \mathrm{PCN}$ ) included structural or organizational delivery components to

\begin{tabular}{|c|c|c|}
\hline \multirow[b]{2}{*}{ Characteristic } & \multicolumn{2}{|c|}{ No. $(\%)$ of programs } \\
\hline & $\begin{array}{l}\text { Alberta Health Services } \\
\qquad n=43\end{array}$ & $\begin{array}{l}\text { Primary Care Networks } \\
\qquad n=15\end{array}$ \\
\hline \multicolumn{3}{|l|}{ Age group of patients served } \\
\hline Children only & $16(37)$ & 0 \\
\hline Adults only (excluding seniors-only programs) & $6(14)$ & $1(7)$ \\
\hline Seniors only & $1(2)$ & 0 \\
\hline All ages & $20(47)$ & $14(93)$ \\
\hline \multicolumn{3}{|l|}{ Targeted clinical conditions } \\
\hline Cancer & $8(19)$ & 0 \\
\hline Cardiovascular disease & $2(5)$ & 0 \\
\hline Kidney disease & $1(2)$ & 0 \\
\hline Chronic disease prevention or management & $2(5)$ & $2(13)$ \\
\hline Substance use disorders and mental health & $10(23)$ & $2(13)$ \\
\hline Developmental or neurologic concerns & $7(16)$ & 0 \\
\hline Other & $2(5)$ & $2(13)$ \\
\hline No specific condition targeted & $11(26)$ & $9(60)$ \\
\hline Self-referral possible & $16(37)$ & $6(40)$ \\
\hline Inpatient program for hospitalized patients only & $2(5)$ & 0 \\
\hline Follow-up provided & $27(63)$ & $13(87)$ \\
\hline \multicolumn{3}{|l|}{ Zones served } \\
\hline North & $5(12)$ & $4(27)$ \\
\hline Edmonton & $9(21)$ & $3(20)$ \\
\hline Central & $7(16)$ & $8(53)$ \\
\hline Calgary & $19(44)$ & 0 \\
\hline South & $3(7)$ & 0 \\
\hline Province-wide & $10(23)$ & 0 \\
\hline
\end{tabular}


maximize efficiency and coordination (e.g., having a multispecialty or interdisciplinary team working together in one geographic location). Out of the 58 programs, 4 (7\%, all AHS) included navigation in the form of Web-based resources, and these were supplemental to the individual patient navigators in the same programs (i.e., the programs were not exclusively Web based). Most AHS $(63 \%, n=27)$ and PCN programs (87\%, $n=13$ ) did provide follow-up, though most commonly on an as-needed basis.

\section{Gaps in patient navigation}

Unmet needs in patient navigation were classified into 4 domains (Table 2). First, there seems to be a lack of awareness of patient navigation programs by all stakeholders, including patients and health care professionals. Information on these programs is not centralized and is not easily accessible, being primarily transmitted through word of mouth. Second, there were identified service gaps for certain populations, specifically for transitional periods, such as for children transitioning to adult care or for hospitalized patients being discharged to the community. Third, geographic coverage of programs was noted to be a concern, with a lack of services provided for those residing in rural communities. Though the programs at urban centres may also serve rural sites owing to their large catchment areas, there are few transportation options for rural residents, resulting in disparate access across the province. Lastly, there was notable lack of cohesion and communication across programs, with programs functioning independently of each other. This issue is exacerbated by the inability to share patient information across the different programs.

\section{Interpretation}

In this study, we found a total of 58 patient navigation programs across Alberta. Most of these are delivered by individual patient navigators. Rather than being uniformly accessible across the population, programs tend to be concentrated in the urban centres and target patients of specific ages or those with specific clinical conditions. Gaps identified in patient navigation include lack of awareness of programs (by patients and health care providers), insufficient resources devoted to the programs, unequal access particularly for those living in rural areas, and poor communication and integration across programs, services and sectors.

There has been 1 prior environmental scan, by Luke and colleagues, ${ }^{47}$ of patient navigation programs in Canada, focusing on the pediatric population. The authors included 23 programs across Canada ( 1 in Alberta). Our environmental scan suggests that patient navigation programs are more prevalent, even when recognizing differences in our inclusion criteria.

The scope of patient navigation programs that we identified differs from the broader literature in 2 ways. First, the literature suggests that most patient navigation programs are cancer related. ${ }^{38}$ This is not surprising, as patient navigation was first developed in cancer screening, ${ }^{39}$ then expanded across the

Table 2: Identified gaps in patient navigation programs and services

\begin{tabular}{|c|c|}
\hline Domain & Specific gaps and unmet needs \\
\hline \multirow[t]{4}{*}{ Awareness } & $\begin{array}{l}\text { Patients, physicians and staff members are unaware of programs and services, including those } \\
\text { - Offered in their zone, through Alberta Health Services } \\
\text { - Offered outside of their zone, through Alberta Health Services } \\
\text { - By organizations outside of Alberta Health Services }\end{array}$ \\
\hline & Owing to lack of patient awareness of programs, programs allowing for self-referral often have a high no-show rate \\
\hline & Information on programs and services is difficult to find and predominantly transmitted through word of mouth \\
\hline & Patients may be aware of programs but do not know how to access them \\
\hline \multirow[t]{2}{*}{ Resources } & Many current patient navigation programs are at or over capacity \\
\hline & $\begin{array}{l}\text { Resources and services are lacking for the following groups: } \\
\text { - Children with complex needs who are transitioning to adult care } \\
\text { - Adults (nonsenior population) } \\
\text { - Adults with mental health and developmental needs } \\
\text { - Patients being discharged from hospital or other acute care facilities } \\
\text { - Those not meeting eligibility criteria of the programs (e.g., young adults with cancer that is not treated by } \\
\text { chemotherapy or radiotherapy) }\end{array}$ \\
\hline \multirow[t]{3}{*}{ Geography } & $\begin{array}{l}\text { Lack of transportation options within cities and from rural residences to programs located at urban sites; it is cost } \\
\text { prohibitive for patients to pay out of pocket to travel from rural residences to larger centres }\end{array}$ \\
\hline & Rural areas have fewer available services \\
\hline & $\begin{array}{l}\text { Patients and care providers from rural areas are unaware of programs and services that they can access at urban } \\
\text { centres }\end{array}$ \\
\hline \multirow[t]{3}{*}{ Integration } & Lack of communication and integration among programs within Alberta Health Services \\
\hline & Lack of cohesive client care and communication across different government ministries \\
\hline & Inability to share and access patient information across different programs \\
\hline
\end{tabular}


cancer care continuum ${ }^{40,48}$ before spreading more broadly. ${ }^{49}$ Our study suggests that patient navigation is no longer isolated to, or even most prevalent in, oncology, but now serves a much broader population. Second, although most patient programs across the United States aim to reduce health disparities ${ }^{9,50}$ (in keeping with the original intent of these programs $s^{5,39}$ ), this does not seem to be the focus of the current programs in Alberta. Only 1 of the identified programs was specifically targeted for vulnerable populations. Few programs explicitly addressed social barriers and social determinants of health. Although the shift in objectives may reflect fundamental differences between health care systems, ${ }^{51}$ it may also signify a critical gap in patient navigation in Alberta, particularly when evidence suggests that socially disadvantaged populations tend to benefit most from patient navigation. ${ }^{52}$

Our study also serves to highlight gaps in knowledge in patient navigation. Not only is there no consensus on a conceptual definition of patient navigation, ${ }^{9,10}$ its operationalization has been broad and varied, ${ }^{53}$ encompassing nearly any service that helps patients overcome obstacles and cope with challenges to their health. ${ }^{10}$ As a result, heterogenous programs - like those identified in this environmental scan — have been developed under the umbrella of "patient navigation," ${ }^{44}$ though they may have little in common. For example, some believe that there must be patient engagement on an individual basis to be considered patient navigation, ${ }^{38}$ whereas others believe that navigation can be delivered without any patient contact. ${ }^{55}$ The construct is even less clear when considering different models of delivery. Although nearly all programs that we identified were delivered by patient navigators, navigators do not appear to be necessary to the construct of patient navigation. For example, 2 scoping reviews on patient navigation identified studies that included either a navigator or the process of navigation. ${ }^{25,26}$ What this process is or entails, however, remains undefined. The general lack of understanding of Web-based and system-level patient navigation has likely contributed to underrecognition of these forms of patient navigation in both the literature and in our environmental scan.

\section{Limitations}

There are limitations to our study. First, our findings are dependent on information provided by respondents. We relied on key informants to identify patient navigation programs across the province; we are likely missing programs, particularly smaller ones or those outside of the major urban centres. We attempted to mitigate this through a large network of key informants in leadership positions, spread across the province. Second, because programs are not well integrated or centralized across the province (even when they have the same objectives), we may not have captured similar programs offered at different sites. For example, though several anticoagulation management programs in different regions were identified by key informants in phase 1 of the study, only the contact of 1 program completed the phase 2 survey. We therefore do not have any information on the other anticoagulation management programs. Third, though we provided a definition of patient navigation to key informants, programs that did not meet prior understanding of patient navigation may not have been identified as relevant and would be missed by our environmental scan. This is a limitation inherent to the field of patient navigation, given the lack of agreement on its definition and construct. Fourth, the scope of our environmental scan was limited to programs delivered by the provincial health authority in Alberta. The characteristics and distribution of patient navigation programs outside of this context may be different. A final limitation is that our environmental scan was conducted in 2016/17. Although there is potential for some recent change in existing programs, health leaders indicate relative stability. Further, this paper is about more than providing a full inventory of existing programs in the jurisdiction. Rather, we demonstrate an approach to organizing a heterogeneous group of interventions, and also highlight the variety of programs and gaps in this field, which are broadly relevant.

\section{Conclusion}

Our study shows an abundance of patient navigation programs in the jurisdiction studied and that they have extended beyond cancer care, from which the construct originated. We found patient navigation programs delivered to the general population in primary care settings, as well as programs targeted to specific groups of patients based on age and presence of certain chronic diseases. Despite the prevalence of these programs, there remain gaps in patient navigation, particularly with respect to lack of awareness of programs, unequal access and lack of emphasis on addressing social vulnerabilities that frequently result in delays in care. These lessons learned can potentially help to shape the future delivery of patient navigation services and programs.

\section{References}

1. Understanding patient and provider experiences with relationship, information, and management continuity. Calgary: Health Quality Council of Alberta; 2016.

2. The reality of caring: distress among the caregivers of home care patients. Toronto: Health Quality Ontario; 2016.

3. Romanow RJ; Commission on the Future of Health Care in Canada. Building on values: the future of health care in Canada. Saskatoon: Privy Council; 2002.

4. Freeman HP, Muth BJ, Kerner JF. Expanding access to cancer screening and clinical follow-up among the medically underserved. Cancer Pract 1995;3:19-30.

5. Freeman HP, Rodriguez RL. The history and principles of patient navigation. Cancer 2011;117:3539-42.

6. Vargas RB, Ryan GW, Jackson CA, et al. Characteristics of the original patient navigation programs to reduce disparities in the diagnosis and treatment of breast cancer. Cancer 2008;113:426-33.

7. Parker VA, Clark JA, Leyson J, et al. Patient navigation: development of a protocol for describing what navigators do. Health Serv Res 2010;45:514-31.

8. Gilbert JE, Green E, Lankshear S, et al. Nurses as patient navigators in cancer diagnosis: review, consultation and model design. Eur $\mathcal{F}$ Cancer Care (Engl) 2011;20:228-36.

9. Dohan D, Schrag D. Using navigators to improve care of underserved patients: current practices and approaches. Cancer 2005;104:848-55.

10. Wells KJ, Battaglia TA, Dudley DJ, et al. Patient navigation: state of the art or is it science? Cancer 2008;113:1999-2010.

11. Ferrante JM, Cohen DJ, Crosson JC. Translating the patient navigator approach to meet the needs of primary care. FABFM 2010;23:736-44.

12. Binswanger IA, Whitley E, Haffey P-R, et al. A patient navigation intervention for drug-involved former prison inmates. Subst Abus 2015;36:34-41.

13. Cantril C, Haylock PJ. Patient navigation in the oncology care setting. Semin Oncol Nurs 2013;29:76-90.

14. Jolly SE, Navaneethan SD, Schold JD, et al. Development of a chronic kidney disease patient navigator program. BMC Nephrol 2015;16:69.

15. Benz Scott L, Gravely S, Sexton TR, et al. Effect of patient navigation on enrollment in cardiac rehabilitation. 7AMA Intern Med 2013;173:244-6. 
16. Ahern DK, Stinson LJ, Uebelacker LA, et al. E-health blood pressure control program. 7 Med Pract Manage 2012;28:91-100.

17. Bradford JB, Coleman S, Cunningham W. HIV System Navigation: an emerging model to improve HIV care access. AIDS Patient Care STDS 2007;21(Suppl 1):S49-58

18. Loskutova NY, Tsai AG, Fisher EB, et al. Patient navigators connecting patients to community resources to improve diabetes outcomes. FABFM 2016;29:78-89.

19. Griswold KS, Homish GG, Pastore PA, et al. A randomized trial: are care navigators effective in connecting patients to primary care after psychiatric crisis? Community Ment Health 7 2010;46:398-402.

20. Battaglia TA, McCloskey L, Caron SE, et al. Feasibility of chronic disease patient navigation in an urban primary care practice. 7 Ambul Care Manage 2012:35:38-49.

21. Patient navigators show the way to faster flow. ED Manag 2007;19:104-5.

22. Enard KR, Ganelin DM. Reducing preventable emergency department utilization and costs by using community health workers as patient navigators. 7 Healthc Manag 2013;58:412-27.

23. Balaban RB, Galbraith AA, Burns ME, et al. A patient navigator intervention to reduce hospital readmissions among high-risk safety-net patients: a randomized controlled trial. 7 Gen Intern Med 2015;30:907-15.

24. Lairson DR, Huo J, Ricks KAB, et al. The cost of implementing a 2-1-1 call center-based cancer control navigator program. Eval Program Plann 2013; 39:51-6.

25. Carter N, Valaitis RK, Lam A, et al. Navigation delivery models and roles of navigators in primary care: a scoping literature review. BMC Health Serv Res 2018;18:96.

26. Peart A, Lewis V, Brown T, et al. Patient navigators facilitating access to primary care: a scoping review. BMF Open 2018;8:e019252.

27. Sofaer S. Navigating poorly charted territory: patient dilemmas in health care "nonsystems." Med Care Res Rev 2009;66:75S-93S.

28. The World Health Report chapter 3: primary care - putting people first. Geneva: World Health Organization; 2008.

29. Robards F, Kang M, Usherwood T, et al. How marginalized young people access, engage with, and navigate health-care systems in the digital age: systematic review. 7 Adolesc Health 2018;62:365-81.

30. Highfield L, Ottenweller C, Pfanz A, et al. Interactive web-based portals to improve patient navigation and connect patients with primary care and specialty services in underserved communities. Perspect Health Inf Manag 2014 Apr 1;11(Spring):1e. PMID: 24808806; PMCID: PMC3995492.

31. Taylor P, Priest L. Personal health navigator: a patient's guide to Ontario's health care system. Toronto: Healthy Debate \& Sunnybrook Health Sciences Centre; 2014.

32. Cancer Journey Portfolio. Navigation: a guide to implementing best practices in person-centred care. Toronto: Canadian Partnership Against Cancer; 2012.

33. Charlton P, Doucet S, Azar R, et al. The use of the environmental scan in health services delivery research: a scoping review protocol. BMF Open 2019; 9:e029805.

34. Graham P, Evitts T, Thomas-MacLean R. Environmental scans. Can Fam Physician 2008;54:1022-3.

35. Rowel R, Moore ND, Nowrojee S, et al. The utility of the environmental scan for public health practice: lessons from an urban program to increase cancer screening. 7 Natl Med Assoc 2005;97:527-34.

36. Primary health care. Alberta: Government of Alberta; 2019. Available: https:// www.alberta.ca/primary-health-care.aspx (accessed 2020 Jan. 21).

37. Wells KJ, Campbell K, Kumar A, et al. Effects of patient navigation on satisfaction with cancer care: a systematic review and meta-analysis. Support Care Cancer 2018:26:1369-82.

38. McBrien KA, Ivers N, Barnieh L, et al. Patient navigators for people with chronic disease: a systematic review. PLoS One 2018;13:e0191980.

39. Freeman HP. The origin, evolution, and principles of patient navigation. Cancer Epidemiol Biomarkers Prev 2012;21:1614-7.

40. Fillion L, Cook S, Veillette A-M, et al. Professional navigation framework: elaboration and validation in a Canadian context. Oncol Nurs Forum 2012; 39:E58-69.

41. Ustjanauskas AE, Bredice $M$, Nuhaily $\mathrm{S}$, et al. Training in patient navigation: a review of the research literature. Health Promot Pract 2016;17:373-81.

42. Wells KJ, Valverde P, Ustianauskas AE, et al. What are patient navigators doing, for whom, and where? A national survey evaluating the types of services provided by patient navigators. Patient Educ Couns 2018;101:285-94.

43. Braun V, Clarke V. Using thematic analysis in psychology. Qual Res Psychol 2006;3:77-101.
44. Garcia J, Evans J, Reshaw M. "Is there anything else you would like to tell us" - methodological issues in the use of free-text comments from postal surveys. Qual Quant 2004;38:113-25.

45. Vaismoradi M, Turunen H, Bondas T. Content analysis and thematic analysis: Implications for conducting a qualitative descriptive study. Nurs Health Sci 2013;15:398-405.

46. Colorafi KJ, Evans B. Qualitative descriptive methods in health science research. HERD 2016;9:16-25

47. Luke A, Doucet S, Azar R. Paediatric patient navigation models of care in Canada: an environmental scan. Paediatr Child Health 2018;23:e46-55.

48. Walkinshaw E. Patient navigators becoming the norm in Canada. CMAf 2011:183:E1109-10.

49. Valaitis RK, Carter N, Lam A, et al. Implementation and maintenance of patient navigation programs linking primary care with community-based health and social services: a scoping literature review. BMC Health Serv Res 2017;17:116.

50. Freund KM. Patient navigation: the promise to reduce health disparities. 7 Gen Intern Med 2011;26:110-2.

51. Thorne $\mathrm{S}$, Truant $\mathrm{T}$. Will designated patient navigators fix the problem? Oncology nursing in transition. Can Oncol Nurs f 2010;20:116-28.

52. Freund KM. Implementation of evidence-based patient navigation programs. Acta Oncol 2017;56:123-7.

53. National Academies of Sciences, Engineering, and Medicine; National Cancer Policy Forum; Board on Health Care Services; Patlak M, Trang C, Nass SJ. Establishing effective patient navigation programs in oncology: proceedings of a workshop. Washington (D.C.): The National Academies Press; 2018. Available: https://doi.org/10.17226/25073 (accessed 2019 Feb. 13).

54. Battaglia TA, Parker VA, McCoy ME, et al. The Boston Medical Center Patient Navigation Toolkit. Boston: Boston Medical Center; 2016.

55. Clark JA, Parker AV, Battaglia AT, et al. Patterns of task and network actions performed by navigators to facilitate cancer care. Health Care Manage Rev 2014;39:90-101.

Affiliations: Department of Medicine (Tang); Department of Community Health Sciences (Tang, Sharma); O' Brien Institute for Public Health (Tang, Ghali); W21C Research and Innovation Centre, Cumming School of Medicine (Kelly, Sharma); Office of the Vice-President (Research) (Ghali), University of Calgary, Calgary, Alta.

Contributors: Karen Tang and William Ghali conceived of the study and were involved in study design. Jenny Kelly and Nishan Sharma conducted data collection. Karen Tang, Jenny Kelly and William Ghali were involved in statistical analyses. All authors were involved in data interpretation. Karen Tang drafted the manuscript and all authors critically revised the manuscript. All authors gave final approval of the version to be published and agreed to be accountable for all aspects of the work.

Funding: No funding was received for this study.

Content licence: This is an Open Access article distributed in accordance with the terms of the Creative Commons Attribution (CC BY-NC-ND 4.0) licence, which permits use, distribution and reproduction in any medium, provided that the original publication is properly cited, the use is noncommercial (i.e., research or educational use), and no modifications or adaptations are made. See: https://creativecommons.org/licenses/ by-nc-nd/4.0/

Data sharing: Owing to restrictions based on participant privacy, data are not available for use by other researchers. Descriptions of some of the programs included in the environmental scan are publicly available at www.informalberta.ca.

Acknowledgments: The authors thank Ms. Sue Conroy and Dr. Francois Belanger for their help in recruiting key informants and study participants, and Ms. Anna Consoli for her assistance with data collection.

Supplemental information: For reviewer comments and the original submission of this manuscript, please see www.cmajopen.ca/content/9/3/ E841/suppl/DC1. 